\title{
The Effect of Omega 3 Fatty Acids Intake on Drug Resistant Epilepsy (DRE) in Children
}

\author{
Mennatallah O Shata*1, Rasha H Aly ${ }^{1}$, Manar A ElHalim ${ }^{2}$ \\ ${ }^{1}$ Department of Pediatrics, Faculty of Medicine, Ain Shams University, Cairo, Egypt. \\ ${ }^{2}$ Department of General Practitioner, Ministry of Health, Cairo, Egypt. \\ *Corresponding author: Mennatallah Osama Shata, Mobile: +201006636930, E-mail: mennahshata@ gmail.com
}

\begin{abstract}
Background: Epilepsy is a frequent neurologic disease in children. Epilepsy is one of humanity's oldest diseases, and it is still the most prevalent neurological disorder afflicting people of all ages. It is estimated that 50 million people worldwide suffer from epilepsy at any given moment.

Objectives: To assess the effect of omega 3 supplementation on seizure control in patients with drug resistant epilepsy, and to compare the effect of the use of low-dose omega 3 versus high dose on seizures control of these patients.

Patients and Methods: The study included 44 patients 26 males (59.1\%) and 18 females (40.9\%) as one patient dropped off during the study. Their mean age was $6.35 \pm 3.59$ years, they were followed up at Outpatient Pediatric Neurology Clinic, Children's Hospital, Ain Shams University.

Results: The primary finding in the current study was that there was a statistically significant decrease in seizure frequency after low-dose omega 3 (1 capsule/day, $1000 \mathrm{mg}$ of eicosapentaenoic (EPA) + docosahexaenoic acid (DHA)). The secondary finding in the current study was that there was a statistically significant decrease in severity of seizures after low-dose fish oil ( 1 capsule/day, $1000 \mathrm{mg}$ of EPA+DHA). The tertiary finding in the current study is that there was no statistically significant decrease in seizure frequency, duration, and severity after high dose omega 3 ( 2 capsules/ day, $2000 \mathrm{mg}$ EPA +DHA) compared with before using omega 3 at the beginning of the study.

Conclusion: Low dose fish oil (1 capsule/day, total of $1000 \mathrm{mg}$ EPA+DHA) was associated with a 50\% reduction in seizure frequency and reduction rate $4.62 \%$ in seizure severity compared with before using omega 3 supplementation in patients of drug resistant epilepsy.
\end{abstract}

Keywords: Drug Resistant Epilepsy, Omega 3 Fatty

Acids.

\section{INTRODUCTION}

Epilepsy is a noncommunicable brain disorder that affects about 50 million individuals worldwide. Recurrent seizures, which are brief periods of involuntary movement involving a section of the body (partial) or the full body (generalised) and are occasionally followed by loss of awareness and control of bowel or bladder function ${ }^{(\mathbf{1})}$.

Medication resistant epilepsy is defined as the failure of adequate trials of two tolerated, adequately chosen and utilised antiepileptic drug regimens (whether as monotherapies or in combination) to achieve persistent seizure independence ${ }^{(2)}$.

Because the brain is one of the organs with the largest concentration of lipids in the form of fatty acids, which play a role in membrane construction, 50 percent of fatty acids in the grey matter are polyunsaturated, with 33 percent belonging to the omega-3 family. The omega-3 fatty acids (mainly alpha-linolenic acid, ALA) participated in one of the first experimental demonstration of the effect of dietary substances on the structure and function of the brain ${ }^{(3)}$.

Bloch and Qawasmi ${ }^{(4)}$ proved that increasing omega-3 fatty acid levels in the diet can affect the structure and function of proteins embedded in the central nervous system by affecting cell membrane fluidity and phospholipid composition.

Omega-3 fatty acids can be obtained through consumption of oily fish - such as a trout, mackerel, tuna, herring, sardines, and salmon - and fish oil supplements ${ }^{(5)}$.

Objectives: To assess the effect of omega 3 supplementation on seizure control in patients with drug resistant epilepsy, and to compare the effect of the use of low-dose omega 3 versus high dose on seizures control of these patients.

\section{PATIENTS AND METHODS}

Prospective case-control randomized, clinical trial of two doses of fish oil: low dose and high dose, in participants with drug resistant epilepsy

The study was conducted on 45 children following up in the Pediatrics Neurology Clinic-Ain Shams Children's Hospital. Patients were classified into three groups \{group 1 receiving low dose omega 3, group 2 receiving high dose omega 3 , group 3 control group \} seizure control was evaluated at recruitment and 3 months after (at the end of the study).

Seizure control was assessed by seizures frequency, seizure duration, and severity using Chalfont 
severity scale at recruitment (before omega 3 supplementation), and three months after omega 3 supplementation. During the study one patient dropped off as his mother noticed that he became hyperactive and anxious, so the total number became 44 patients 26 males $(59.1 \%)$ and 18 females $(40,9 \%)$ their mean age was $6.35 \pm 3.59$ years.

Inclusion criteria: Patients with age range from 2-15 years. Patients with drug resistant epilepsy \{which is defined by ILAE as failure of adequate trials of two tolerated, appropriately chosen and used antiepileptic drug schedules (whether as monotherapies or in combination) to achieve sustained seizure freedom\}. And patients agreeing to keep their antiepileptic drug regimen constant throughout the period of the study.

Exclusion criteria: Significant or progressive medical, cardiac, or other illness, allergy to fish products or fish oil, history of a coagulation disorder, consumption of fish oil at any time 30 days or less prior to enrollment, and any change in antiepileptic drugs for 30 days or fewer prior to enrollment.

\section{Subjects:}

Group (1): It was comprised of 15 patients (6 females and 9 males), their mean age was $5.97 \pm 4.14$ with drug resistant epilepsy who received low dose fish oil supplement: one fish oil supplement daily in the form of one capsule; the equivalent of $1000 \mathrm{mg}$ of omega 3 (13\% EPA, 9\% DHA and 52-59\% linoleic acid).

Group (2): It was comprised of 15 patients with drug resistant epilepsy on high dose fish oil supplement: two fish oil supplements daily in the form of two capsules; the equivalent of $2000 \mathrm{mg}$ of omega 3 . During the study one patient dropped off as his mother noticed hyperactivity in his behavior and increase in his seizure's frequency so the total number of this group became 14 patients (5 females and 9 males), their mean age was $6.42 \pm 3.47$.

Group (3): It was comprised of 15 patients (7 females and 8 males), their mean age was $6.76 \pm 3.29$ with drug resistant epilepsy who did not receive omega 3 as a control group.

\section{Ethical consent:}

An approval of the study was obtained from Ain Shams University Academic and Ethical Committee. Informed written consent was obtained from parents of all children participants before recruitment in the study, after explaining the objectives of the work. This work was carried out in accordance with the Code of Ethics of the World Medical Association (Declaration of Helsinki) for studies involving humans.

All patients were subjected to the following:

1. Full history taking: History of seizures, including, age of onset, duration of seizures, severity of seizures, type of seizures, type of epilepsy and antiepileptic drugs (AEDS) history (name, number, dose, and duration), description of the condition (precipitating factors, number of attacks and drugs received in management of the condition).

2. Thorough general and neurological clinical examination to verify criteria of diagnosis.

3. Assessment of frequency of seizures, duration of seizures per month, severity of seizures using Chalfont seizures severity scale.

4. Investigations done to all patients on initial disease diagnosis included:

A) Routine: complete blood picture (CBC), liver function tests: serum alanine transaminase (ALT), serum aspartate transaminase (AST), serum alkaline phosphatase (ALP).

1- Renal function tests (serum urea, creatinine).

2- Serum electrolytes (sodium, potassium, calcium, magnesium) and blood glucose.

B) Electroencephalogram (EEG)

C) Neuroimaging \{Computerized tomography (CT scan) + Magnetic Resonance Imaging (MRI) $\}$

\section{Statistical Analysis}

Data were collected, revised, coded, and entered to the Statistical Package for the Social Sciences (IBM SPSS) version 20. Qualitative data were presented as number and percentages while quantitative data were presented as mean, standard deviations and ranges when parametric and median with interquartile ranges (IQR) with nonparametric data. $\mathrm{P}<0.05$ was considered significant and $\mathrm{P}<0.01$ highly significant.

\section{RESULTS}

The current study included 26 males $(59.1 \%)$ and 18 females $(40.9 \%)$. Their mean age was 6.35 \pm 3.59 years and they were exhibiting various forms of seizures. The primary finding in the current study was that using low-dose fish oil (1 capsules/day, $1000 \mathrm{mg}$ of EPA+DHA) for three months was associated with a $50 \%$ reduction in seizure frequency compared with before fish oil supplementation (Table 1). 
Table (1): Descriptive data of the patients as regard age, sex, type of seizures, type of epilepsy, frequency of seizure, duration of seizure attack, Chalfont severity scale and number of AEDs

\begin{tabular}{|c|c|c|c|c|}
\hline & Control group & Low dose & High dose \\
\hline & & No. $=15$ & No. $=15$ & No. $=14$ \\
\hline Age (Year) & $\begin{array}{c}\text { Mean } \pm \text { SD } \\
\text { Range }\end{array}$ & $\begin{array}{c}6.67 \pm 3.29 \\
3-13 \\
\end{array}$ & $\begin{array}{c}5.97 \pm 4.14 \\
2-14 \\
\end{array}$ & $\begin{array}{c}6.42 \pm 3.47 \\
3-13 \\
\end{array}$ \\
\hline Sex & $\begin{array}{c}\text { Female } \\
\text { Male }\end{array}$ & $\begin{array}{l}7(46.7 \%) \\
8(53.3 \%)\end{array}$ & $\begin{array}{l}6(40.0 \%) \\
9(60.0 \%)\end{array}$ & $\begin{array}{l}5(35.70 \%) \\
9(64.30 \%)\end{array}$ \\
\hline Type of Seizures & $\begin{array}{c}\text { Focal } \\
\text { Generalized }\end{array}$ & $\begin{array}{l}7(46.67 \%) \\
8(53.33 \%) \\
\end{array}$ & $\begin{array}{c}5(33.33 \%) \\
10(66.67 \%)\end{array}$ & $\begin{array}{l}4(26.67 \%) \\
10(66.67 \%)\end{array}$ \\
\hline Type of Epilepsy & $\begin{array}{l}\text { Non idiopathic } \\
\text { Idiopathic }\end{array}$ & $\begin{array}{l}9(60.0 \%) \\
6(40.0 \%)\end{array}$ & $\begin{array}{l}12(80.0 \%) \\
3(20.0 \%)\end{array}$ & $\begin{array}{c}9(64.3 \%) \\
5(35.70 \%)\end{array}$ \\
\hline $\begin{array}{c}\text { Frequency of seizure } \\
\text { Attack / Week }\end{array}$ & Mean \pm SD & $7.07 \pm 7.14$ & $13.13 \pm 12.02$ & $7.29 \pm 8.56$ \\
\hline $\begin{array}{c}\text { Duration of seizure } \\
\text { Attack }\end{array}$ & $\begin{array}{l}<1 \text { Min } \\
>10 \text { Min } \\
1-10 \text { Min }\end{array}$ & $\begin{array}{l}5(33.3 \%) \\
7(46.7 \%) \\
3(20.0 \%)\end{array}$ & $\begin{array}{l}3(20.0 \%) \\
5(33.3 \%) \\
7(46.7 \%)\end{array}$ & $\begin{array}{l}2(14.29 \%) \\
7(50.0 \%) \\
5(35.71 \%)\end{array}$ \\
\hline Chalfont severity scale & Mean \pm SD & $52.2 \pm 39.16$ & $58.80 \pm 25.24$ & $48.71 \pm 35.03$ \\
\hline \multicolumn{5}{|c|}{ No. of antiepileptic drugs (AEDs) } \\
\hline $\begin{array}{r}\text { Two } \\
\text { Three } \\
\text { Total }\end{array}$ & & $\begin{array}{c}15(100.00 \%) \\
0(0.00 \%) \\
15(100 \%)\end{array}$ & $\begin{array}{c}10(66.70 \%) \\
5(33.30 \%) \\
15(10 \%)\end{array}$ & $\begin{array}{l}11(78.60 \%) \\
3(21.40 \%) \\
14(100 \%)\end{array}$ \\
\hline
\end{tabular}

Before omega 3 supplementation, patients with drug resistant epilepsy demonstrated a nonsignificant statistical difference between the three groups as regards frequency of attacks, duration of attack and Chalfont severity scale (Table 2).

Table (2): Comparison between three groups as regard the frequency of attack, duration of attack and Chalfont severity scale before omega 3 supplementation.

\begin{tabular}{|c|c|c|c|c|c|}
\hline \multirow{2}{*}{\multicolumn{2}{|c|}{$\begin{array}{c}\text { Before Omega } 3 \\
\text { Supplementation }\end{array}$}} & \multirow{3}{*}{$\begin{array}{c}\text { Control group } \\
\text { No. }=\mathbf{1 5} \\
7.07 \pm 7.14\end{array}$} & \multirow{3}{*}{$\begin{array}{c}\text { Low dose } \\
\text { No. }=\mathbf{1 5} \\
13.13 \pm 12.02\end{array}$} & \multirow{3}{*}{$\begin{array}{c}\text { High dose } \\
\text { No. }=14 \\
7.29 \pm 8.56\end{array}$} & \multirow{3}{*}{$\begin{array}{c}\mathbf{P} \\
0.155\end{array}$} \\
\hline & & & & & \\
\hline $\begin{array}{c}\text { Frequency of } \\
\text { Attacks / Week }\end{array}$ & Mean \pm SD & & & & \\
\hline Duration of Attack & $\begin{array}{c}<1 \mathrm{Min} \\
>10 \mathrm{Min} \\
1-10 \mathrm{Min}\end{array}$ & $\begin{array}{l}5(33.3 \%) \\
7(46.7 \%) \\
3(20.0 \%)\end{array}$ & $\begin{array}{l}3(20.0 \%) \\
5(33.3 \%) \\
7(46.7 \%)\end{array}$ & $\begin{array}{c}2(14.29 \%) \\
7(50.0 \%) \\
5(35.71 \%)\end{array}$ & 0.503 \\
\hline Chalfont severity scale & Mean \pm SD & $52.2 \pm 39.16$ & $58.80 \pm 25.24$ & $48.71 \pm 35.03$ & 0.663 \\
\hline
\end{tabular}

After omega 3 supplementation there was non-significant statistical difference between the three groups as regards frequency of attacks, duration of attack and Chalfont severity scale (Table 3).

Table (3): Comparison between three groups as regard frequency of attack, duration of attack and Chalfont severity scale after omega 3 supplementation

\begin{tabular}{|c|c|c|c|c|c|}
\hline \multirow{2}{*}{\multicolumn{2}{|c|}{$\begin{array}{c}\text { After Omega } 3 \\
\text { Supplementation }\end{array}$}} & $\begin{array}{c}\text { Control } \\
\text { group }\end{array}$ & $\begin{array}{l}\text { Low } \\
\text { dose }\end{array}$ & $\begin{array}{l}\text { High } \\
\text { dose }\end{array}$ & \multirow[t]{2}{*}{$\mathbf{P}$} \\
\hline & & No. $=15$ & No. $=15$ & No. $=14$ & \\
\hline $\begin{array}{c}\text { Frequency of } \\
\text { Attacks / Week }\end{array}$ & Mean \pm SD & $7.6 \pm 6.78$ & $6.87 \pm 8.91$ & $8.36 \pm 8.98$ & 0.889 \\
\hline $\begin{array}{l}\text { Duration of } \\
\text { Attack }\end{array}$ & $\begin{array}{l}<1 \mathrm{Min} \\
>10 \mathrm{Min} \\
1-10 \mathrm{Min}\end{array}$ & $\begin{array}{l}5(33.3 \%) \\
7(46.7 \%) \\
3(20.0 \%)\end{array}$ & $\begin{array}{l}7(46.7 \%) \\
2(13.3 \%) \\
6(40.0 \%)\end{array}$ & $\begin{array}{l}2(14.3 \%) \\
6(42.9 \%) \\
6(42.9 \%)\end{array}$ & 0.155 \\
\hline Chalfont severity scale & Mean \pm SD & $54.87 \pm 39.85$ & $52.47 \pm 25.83$ & $51.93 \pm 36.37$ & 0.970 \\
\hline
\end{tabular}

There was a highly statistically significant decrease in frequency of attacks and Chalfont severity scale after low dose omega 3 supplementation (Table 4). 
Table (4): Comparison in low dose group as regards frequency of attacks, duration of attack and Chalfont severity scale before and after omega 3 supplementation

\begin{tabular}{|c|c|c|c|c|}
\hline \multicolumn{2}{|c|}{} & $\begin{array}{c}\text { Before } \\
\text { No. }=15\end{array}$ & $\begin{array}{c}\text { After } \\
\text { No. }=15\end{array}$ & P \\
\hline $\begin{array}{c}\text { Frequency of Attack } \\
\text { / Week }\end{array}$ & Mean \pm SD & $13.13 \pm 12.02$ & $6.87 \pm 8.91$ & 0.003 \\
\hline \multirow{2}{*}{ Duration of Attack } & $<1$ Min & $3(20.00 \%)$ & $7(46.70 \%)$ & \\
& $>10$ Min & $5(33.3 \%)$ & $2(13.30 \%)$ \\
$6(40.00 \%)$ & 0.227 \\
\hline Chalfont severity scale & Mean \pm SD & $59.80 \pm 25.24$ & $52.47 \pm 25.83$ & 0.012 \\
\hline
\end{tabular}

There was a nonsignificant statistical difference in frequency of attacks, duration of attack and Chalfont severity scale after high dose omega 3 supplementation (Table 5).

Table (5): Comparison in high dose group as regards frequency of attack, duration of attack and Chalfont severity scale before and after omega 3 supplementation

\begin{tabular}{|c|c|c|c|c|}
\hline \multicolumn{2}{|c|}{} & $\begin{array}{c}\text { Before } \\
\text { No. = 14 }\end{array}$ & $\begin{array}{c}\text { After } \\
\text { No. }=\mathbf{1 4}\end{array}$ & P \\
\hline $\begin{array}{c}\text { Frequency of Attack } \\
\text { / Week }\end{array}$ & Mean \pm SD & $7.29 \pm 8.56$ & $8.36 \pm 8.98$ & 0.096 \\
\hline \multirow{2}{*}{ Duration of Attack } & $<1 \mathrm{Min}$ & $2(14.3 \%)$ & $2(14.3 \%)$ & \multirow{6}{*}{$(42.9 \%)$} \\
& $>10 \mathrm{Min}$ & $7(50.0 \%)$ & 0.919 \\
\hline Chalfont severity scale & Mean \pm SD & $48.71 \pm 35.03$ & $51.93 \pm 36.37$ & 0.095 \\
\hline
\end{tabular}

Table 6 shows that there was a reduction rate of $50 \%$ in frequency of seizures in low dose group and $4.62 \%$ in severity of seizures in low dose group while in control and high dose groups there was $0 \%$ reduction (Table 6).

Table (6): Comparison between three groups as regard reduction rate in frequency of seizures and severity of seizure

\begin{tabular}{|c|c|c|c|c|c|}
\hline \multicolumn{2}{|c|}{ Reduction rate } & $\begin{array}{c}\text { Control } \\
\text { group }\end{array}$ & $\begin{array}{c}\text { Low } \\
\text { dose }\end{array}$ & $\begin{array}{c}\text { High } \\
\text { dose }\end{array}$ & \multirow{2}{*}{ P } \\
\cline { 3 - 6 } & No.=15 & No. = 15 & No. = 14 & \\
\hline $\begin{array}{c}\text { Frequency of } \\
\text { Attacks }\end{array}$ & Median (IQR) & $0(0-42.86)$ & $-50(-66.67--25)$ & $0(0-28.57)$ & $<0.001$ \\
\hline $\begin{array}{c}\text { Chalfont } \\
\text { severity } \\
\text { scale }\end{array}$ & Median (IQR) & $0(0-0)$ & $-4.62(-26.79-0)$ & $0(0-0)$ & $<0.001$ \\
\hline
\end{tabular}

\section{DISCUSSION}

The current study included 26 males $(59.1 \%)$ and 18 females $(40.9 \%)$ as one patient dropped off during the study. Their mean age was $6.35 \pm 3.59$ years and they were exhibiting various forms of seizures. The primary finding in the current study was that using low-dose fish oil (1 capsules/day, $1000 \mathrm{mg}$ of EPA+DHA) for three months was associated with a $50 \%$ reduction in seizure frequency compared with before low dose fish oil supplementation.

This in accordance with DeGiorgio et al. (5) study who reported that low-dose fish oil (3 capsules/day, total of $1080 \mathrm{mg}$ EPA+DHA) was associated with a $33.6 \%$ reduction in seizure frequency compared with placebo in a randomized placebocontrolled trial of low dose and high-dose fish oil versus placebo (corn oil, linoleic acid) in 24 participants with drug resistant epilepsy. This is also in accordance with Reda $\boldsymbol{e t}$ al. ${ }^{(\boldsymbol{6})}$ who found that omega 3 polyunsaturated fatty acids elevated the seizure threshold in epileptic patients and may help in achieving seizure control in their case control study, where a total of 70 children with medically resistant epilepsy underwent assessment of the frequency and severity of the epileptic attacks at baseline, after one month, two months and three months from the beginning of the study; 35 children received fish oil for three months a 3-milliliter daily dose of $1200 \mathrm{mg}$ fish oil providing $240 \mathrm{mg}$ DHA and $360 \mathrm{mg}$ EPA, while the other 35 children received placebo. The number of children who received fish oil, having 0 epileptic attacks increased from $0 \%$, before starting the study, up to $57.1 \%$ at the end of the third month, while the improvement was minimal in the placebo group, with a significant difference in the improvement between the intervention and the control groups, in both groups, 
children continued to take their antiepileptic treatments.

Al Khayat et al. ${ }^{(7)}$ also revealed a negative correlation between DHA and EPA plasma concentration and seizure frequency, duration, and severity after studying the anticonvulsant effect of n-3 polyunsaturated fatty acids (PUFAs) on 20 children with idiopathic intractable epilepsy on antiepileptic drug polytherapy and twenty healthy age and sex matched controls. Serum levels of alpha-linolenic acid (ALA) (omega-3), eicosapentaenoic acid (EPA) (omega-3), docosapentaenoic acid (DPA) (omega-3), docosahexaenoic acid (DHA) (omega-3), linoleic acid (LA) (omega-6) and arachidonic acid (omega-6) were assessed by gas liquid chromatography. Prior to oral PUFAs supplementations, patients with intractable epilepsy had lower levels of DHA, DPA and higher levels of ALA, EPA and LA compared to controls. After 6 months of oral PUFAs supplementation, compared with healthy controls, levels of DHA was increased while, ALA, LA, EPA, DPA and arachidonic acid were decreased; while comparing to levels before supplement; furthermore, there were an increase in levels of DHA, DPA as well as DHA: EPA and LA: ALA ratios and a decrease in ALA, LA and EPA levels in patients following supplementation compared to their levels prior to oral supplementation. Both the changes in serum levels of PUFAs and their ratios were accompanied by decrease in seizure frequency, duration and severity. There was a significant negative correlation between serum DHA level and seizure duration as well as seizure severity. Altered serum levels of omega three and six PUFAs were associated with uncontrolled seizures, and oral supplementation with DHA and EPA lead to better seizure control.

The secondary finding in the current study was that there was a statistically significant decrease in severity of seizures after low-dose fish oil (1 capsules/day, $1000 \mathrm{mg}$ of EPA+DHA) for three months, which was associated with a $4.62 \%$ reduction in seizure compared with before fish oil supplementation. In contrary to our study, Reda et al. (6) found non statistically significant difference in improvement in the severity of the seizures either between cases and control or between the beginning (before omega 3) and the end of the study (after 3 months of omega 3 ).

The tertiary finding in the current study was that there was no statistically significant decrease in seizures frequency, duration and severity after high dose omega 3 ( 2 capsules/ day, 2000 mg EPA +DHA) compared with before using omega 3 at the beginning of the study. Similar to the current study DeGiorgio et al. ${ }^{(5)}$ reported that high-dose fish oil (3 capsules twice/day, total of $2160 \mathrm{mg}$ EPA+DHA) was associated with no different than placebo in reducing seizures frequency. And Yuen et al. ${ }^{(8)}$ first reported a randomized placebo controlled parallel trial of fish oil for epilepsy in 58 participants with epilepsy, in which 1700 $\mathrm{mg}$ of EPA+DHA was administered daily. No side effects or antiepileptic drug interactions were reported. Initially, a significantly higher number of participants on fish oil experienced a greater than $50 \%$ reduction in seizures in the first 6 weeks of the treatment period; however, over the entire 12-week treatment period, there was no significant difference in responder rate for the treatment versus control. Between-group differences in seizure frequencies at baseline may have made it difficult to detect true differences, a phenomenon common in epilepsy clinical trials.

The lack of efficacy of high-dose fish oil in this trial is consistent with data from recent animal study by Trépanier $\boldsymbol{e t} \boldsymbol{a l}$. (9) who reported that administration of high-dose n-3 fatty acids (DHA, 600 $\mathrm{mg} / \mathrm{kg}$ ) exacerbate seizures in a pentylenetetrazole model. This is in direct contrast to lower doses of DHA $(<400 \mathrm{mg} / \mathrm{kg})$, which exhibit an anticonvulsant effect. Similarly, rats, which are genetically resistant to seizures, experience a significant increase in susceptibility to kindling when exposed to high dose fish oil (1000 mg/kg of EPA, $700 \mathrm{mg} / \mathrm{kg}$ of DHA).

Bromfield et al. ${ }^{(10)}$ reported a randomized controlled trial in 21 participants with drug resistant epilepsy using a higher dose of fish oil $(2200 \mathrm{mg} / \mathrm{day}$ of EPA and DHA). During the acute treatment period, fish oil supplementation was associated with an increased seizure frequency of $6 \%$ versus a reduction of $12 \%$ with placebo. However, after conclusion of the 12-week randomized trial, long-term treatment was associated with significant reductions in seizures, with $5 / 19$ participants experiencing a 50\% reduction in seizures, many of whom (4/5) were originally randomized to placebo.

In contrary to our study Abdel-Wahab et al. (11) proved in his study on rats that a relatively large dose levels of omega $3(200-500 \mathrm{mg} / \mathrm{kg})$ effectively attenuated seizures and their cognitive deficits in kindled young rats.

Flores-Mancilla et al. ${ }^{(12)}$ found that chronic supplementation with omega-3 of marine origin may have antiseizure properties in the study by evaluating the effect of long-term chronic fish oil (FO) supplementation (from embryonic conception to adulthood) on the severity of seizures and amygdaloid electroencephalographic activity (EEG) in a 3 mercaptopropionic acid (3-MPA)-induced seizure model using adult rats. Female Wistar rats were fed a commercial diet supplemented daily with FO (300 $\mathrm{mg} / \mathrm{kg}$ ) from puberty through mating, gestation, delivery, and weaning of the pups. Only the male pups were then fed daily with a commercial diet supplemented with the same treatment as the dam up to the age of 150 days postpartum, when they were bilaterally implanted in the amygdala to record behavior and EEG activity before, during, and after seizures induced by administering 3-MPA. Results were compared with those obtained from rats supplemented with palm oil (PO) and rats treated with 
a vehicle (Control). The male rats treated with FO showed longer latency to seizure onset, fewer convulsive episodes, and attenuated severity compared those in the PO and control groups according to the Racine scale.

\section{CONCLUSION}

From our study, we can conclude that low dose fish oil (1 capsule/day, total of $1000 \mathrm{mg}$ $\mathrm{EPA}+\mathrm{DHA}$ ) was associated with a $50 \%$ reduction in seizure frequency and reduction rate of $4.62 \%$ in seizure severity compared with before using omega 3 supplementation in patients of drug resistant epilepsy. On the other hand, high dose omega 3 showed no statistically significant decrease in seizure frequency and severity.

A large randomized controlled trial of fish oil is warranted to confirm or refute the findings of this study. Omega-3 dietary polyunsaturated fatty acids have promising effects in decreasing seizures frequency and severity.

\section{REFERENCES}

1. WHO (2019): Epilepsy. https://www.who.int/newsroom/fact-sheets/detail/epilepsy

2. Kwan P, Arzimanoglou A, Berg A et al. (2010): Definition of drug resistant epilepsy: consensus proposal by the ad hoc task force of the ILAE commission on therapeutic strategies. Epilepsia, 51(6):1069-77

3. Bourre $\mathbf{J}$ (2005): Omega-3 fatty acids in psychiatry. Med Sci (Paris), 21(2):216-21.

4. Bloch M, Qawasmi A (2011): Omega-3 fatty acid supplementation for the treatment of children with attention-deficit/hyperactivity disorder symptomatology. Am Acad Child Adolesc Psychiatry, 50(10): 991-1000.

5. DeGiorgio $C$, Miller $P$, Harper $R$ et al. (2014): Fish oil (n-3 fatty acids) in drug resistant epilepsy: a randomized placebo-controlled crossover study. J Neurol Neurosurg Psychiatry, 86(1):65-70.

6. Reda D, Abd ElFatah N, Omar T et al. (2015): Fish oil intake and seizure control in children with medically resistant epilepsy. N Am J Med Sci., 7(7): 317-321.

7. Al Khayat H, Awadalla M, Al Wakad A et al. (2010): Polyunsaturated fatty acids in children with idiopathic intractable epilepsy: Serum levels and therapeutic response. J Pediatr Neurol., 8:175-85.

8. Yuen A, Sander J, Fluegel D et al. (2005): Omega3 fatty acid supplementation in patients with chronic epilepsy: a randomized trial. Epilepsy Behav., 7: 253-8.

9. Trépanier M, Taha A, Mantha $\mathrm{R}$ et al. (2012): Increases in seizure latencies induced by subcutaneous docosahexaenoic acid are lost at higher doses, Epilepsy Res., 99 (2012) 225-232.

10. Bromfield E, Dworetzky B, Hurwitz $S$ et al. (2008): A randomized trial of polyunsaturated fatty acids for refractory epilepsy. Epilepsy Behav., 12:187-90.

11. Abdel-Wahab B, Shaikh I, Khateeb $M$ et al. (2015): Omega 3 polyunsaturated fatty acids enhance the protective effect of levetiracetam against seizures, cognitive impairment and hippocampal oxidative DNA damage in young, kindled rats. Pharmacol Biochem Behav., 135:105-13.

12. Flores-Mancilla L, Hernández-González $M$, Guevara M et al. (2014): Long-term fish oil supplementation attenuates seizure activity in the amygdala induced by 3-mercaptopropionic acid in adult male rats. Epilepsy Behav., 33:126-34. 